Aletria, Belo Horizonte, v. 28, n. 4, p. 47-63, 2018

\title{
A representação do negro em sociedades escravocratas das Américas: história, literatura e artes visuais
}

\section{Negroes Representation in Slavocratic Americans Societies: History, Literature and Visual Arts}

\author{
Solange Ribeiro de Oliveira \\ Universidade Federal de Minas Gerais (UFMG), Belo Horizonte, Minas Gerais / Brasil \\ solanger1@uol.com.br
}

Resumo: Apoiado no testemunho de artistas e historiadores, o artigo argumenta que o objeto artístico pode atuar tanto para reforçar quanto para contestar tradições incrustadas na memória coletiva das nações. Nesse sentido, analisa o papel da arte visual como tão importante quanto o de documentos escritos da história e da literatura. A título de exemplo, focalizam-se diferentes formas de representação do negro em sociedades escravocratas, começando com a pintura oitocentista de Jean-Baptiste Debret. Seguese a análise da função da fotografia, que, inventada no mesmo século, mostrou-se igualmente enredada nos fatos sociais. Nas artes contemporâneas, o trabalho destaca a atuação contestadora de Fred Wilson, artista e historiador norte-americano, de Adriana Varejão e dos poetas Márcio Barbosa e Oliveira Silveira.

Palavras-chave: representação do negro; sociedades escravocratas; fotografia.

Abstract: Relying on the testimony of artists and historians, the article argues that artistic objects can contribute both to reinforce and to contest traditions enshrined in the collective memory of nations. The text recalls the role of visual arts as no less important than that of written documents. For instance, it focuses on different forms of representing negroes in slavocratic societies, starting with the nineteenth-century work of Jean-Baptiste Debret, following an analysis of the role of photography, art that was invented in the same century which proved equally intertwined with social facts. In contemporary art, the article discusses the contesting function of the North-American artist and historian Fred Wilson's work, as well as that of Adriana Varejão and of poets Márcio Barbosa and Oliveira Silveira.

Keywords: Representations of negroes; slavocratic societies.

eISSN: 2317-2096

DOI: $10.17851 / 2317-2096.28 .4 .47-63$ 
O estudo da representação da cultura na literatura e nas artes encontra sólido apoio na produção de artistas, críticos e pesquisadores que, através dos tempos, vêm se debruçando sobre a relação entre a criação artística e os estudos históricos, literários e culturais. No que diz respeito à relação entre história e pintura, começo por lembrar que, já em Della pintura (1435-1436), primeiro tratado moderno sobre a teoria da pintura, Leon Battista Alberti, paladino da vanguarda de seu tempo, afirma: "a pintura contém uma força divina, que não apenas torna presentes os ausentes, mas, sobretudo, [...] quase faz parecer vivos os mortos." ${ }^{1}$ Com essas palavras, Alberti oferece uma sugestão embrionária do valor documental do objeto artístico, antecipando desdobramentos e observações mais explícitas, presentes, séculos afora, na prática e na teoria do mundo da arte.

Entre as obras, destaco o sentido subjacente à $A$ arte da pintura (The art of painting), ${ }^{2}$ óleo de Johannes Vermeer (1632-1675), vindo à luz dois séculos após o tratado de Alberti. O quadro mostra um artista pintando uma jovem coroada de louros, tendo numa das mãos um livro e na outra, uma trombeta. Esses acessórios têm sido vistos como referências à memória histórica, perpetuada pela escrita, e à interpretação da figura feminina como uma representação de Clio, musa da história. Lado a lado com a alusão à pintura como serva da história, pode-se ler a tela como uma referência ao poder do artista de, como queria Alberti, ressuscitar o passado.

Na sequência dessas ideias, ainda no século XVII, críticos de arte consideravam a pintura e a escultura histórica como gêneros superiores. Em fins do século XVIII consolidou-se esse entendimento, que se prolonga na Europa do século XIX, quando a pintura histórica passa a ser cultuada como manifestação da identidade e da cultura das nações. No Brasil, círculos acadêmicos e sociais contribuíram para reforçar essa ideia, apoiando-se em obras memoráveis como A primeira missa (1860), O combate naval do Riachuelo (1882-1883) e A batalha de Guararapes

\footnotetext{
1 "Painting contains a divine force which not only makes absent men present [...] but moreover makes the dead almost seem alive" (ALBERTI. On Painting, Book II, p. 63, tradução minha). Em sua introdução ao livro de Alberti, John R. Spencer, tradutor e pesquisador de sua obra, observa que essas palavras remetem a uma afirmação de Cícero, em De amicitia, vii, 23 (ALBERTI. On Painting, Book II).

${ }^{2}$ Para acessar as imagens analisadas neste trabalho, clique sobre seus títulos. As referências completas encontram-se ao final do texto [N.E.].
} 
(1879), de Victor Meirelles, bem como A batalha do Campo Grande (1871) e A batalha do Avai (1877), de Pedro Américo, que colaboraram para a criação de uma iconografia e uma simbologia próprias.

$\mathrm{Na}$ contemporaneidade, especialistas em história e estudos culturais retomam o tema transecular, enfatizando a relação entre suas pesquisas e a história da arte. Com esse objetivo, esforçam-se por documentar suas fontes, acrescentando o estudo de imagens e artefatos à prática tradicional, por tanto tempo dominada pelo discurso verbal. A propósito, Jürgen E. Müller, teórico dos estudos de intermidialidade, aponta como a abordagem mais apropriada para qualquer tipo de pesquisa intermidiática "um conceito de mídia semiológico ou funcional, que relaciona as mídias aos processos socioculturais e históricos". ${ }^{3}$ Essa confluência de abordagens prolonga-se no entrelaçamento da sociologia com a literatura. No Brasil, basta citar Gilberto Freyre, cuja obra inclui dons de literato, louvados por testemunhos insuspeitos. Eduardo Portella comenta seu "estilo de características nítidas e pessoais." Manuel Bandeira atribui-lhe "as virtualidades de um grande poeta [para o qual] não existem fronteiras rígidas entre a região da poesia e a da ciência". ${ }^{5}$ Osman Lins chega a atribuir ao sociólogo certa influência sobre a literatura brasileira. ${ }^{6}$

Para o tema deste trabalho - a representação do negro nas artes - um quadro, polêmico na época, revela-se de especial interesse. Pela primeira vez, em A batalha do Avai, Pedro Américo rompe com o silêncio iconográfico e apresenta imagens de negros lutando ao lado de soldados brancos na guerra do Paraguai. Veladamente, um pintor renomado aborda, pela primeira vez, a espinhosa questão da escravidão. A crítica se dividiu a respeito. Ler-se-ia no quadro uma acusação aos senhores que se furtaram a combater, enviando escravos em seu lugar? Seria Pedro Américo abolicionista? Entretanto, o quadro constitui uma manifestação esporádica, tal qual sucedera com a literatura no século anterior, quando a poesia de Santa Rita Durão (1722-1784) e de Basílio da Gama (1740-1795) só se referiu aos negros como colaboradores dos brancos na defesa do trono português.

\footnotetext{
${ }^{3}$ MÜLLER. Intermidialidade revisitada, p. 76.

${ }^{4}$ PORTELLA. Gilberto Freyre e a renovação do romance brasileiro, p. 400.

${ }^{5}$ BANDEIRA. Gilberto Freyre, poeta, p. 79.

${ }^{6}$ LINS. Breve contribuição a um possível estudo acerca da influência de Gilberto Freyre sobre a literatura brasileira, p. 306-311.
} 
Curiosamente, na pintura do século XIX, coube a um pintor estrangeiro, Jean-Baptiste Debret (1768-1848), abordar frontalmente o tratamento reservado ao negro no Brasil. Etnógrafo e artista formado pela Academia Francesa de Belas Artes, Debret permaneceu no país entre 1816 e 1831, como membro da chamada Missão Artística Francesa, principal acontecimento cultural do século. Dificilmente, tanto no aspecto formal quanto no temático, encontrar-se-ia contraste mais contundente entre o artista francês e os grandes pintores brasileiros. Vitor Meireles e Pedro Américo, em monumentais quadros a óleo, construíram cenas históricas, visando à criação de uma memória coletiva povoada de feitos heroicos. Debret, pelo contrário, escolheu a simplicidade do desenho e da aquarela para abordar temas inovadores: festas populares, espetáculos de rua e o cotidiano das classes trabalhadoras. Alguns de seus quadros ostentam um realismo cru, tão chocante, que sua exibição foi proibida pelo Instituto Histórico e Geográfico. Merecem particular interesse suas representações de negros labutando na lavoura, molambentos, quase nus, sujeitos a punições de indizível crueldade. Veja-se a aterradora representação do chicoteamento de um escravo. O infeliz tem os punhos atados por cordas e traves horizontais presas entre as pernas, deixando a cabeça exposta aos açoites, como na aquarela Castigo de escravo, que mostra um feitor açoitando um negro.

O pincel de Debret deixou-se também atrair por cenas menos penosas, que nem por isso dispensam reflexões inquietantes. A conhecidíssima aquarela Um jantar brasileiro, de 1827, mostra uma família de senhores brancos jantando tranquilamente, servidos por escravos. O dono da casa concentra-se gulosamente na comida. Sua esposa, com o braço esquerdo pousado sobre a mesa, abaixa o direito para oferecer um bocado a um negrinho nu sentado a seus pés - como poderia fazer com um cãozinho. Mais afastado, outro menino negro come também. Não se pode deixar de especular que as duas crianças sejam filhos do dono da casa. Como se sabe, a escravidão atingia todos os aspectos da vida familiar, incluindo estupros de escravas, que geravam crianças bastardas, de situação ambígua, ocasionalmente tratadas como filhos, que poderiam até tornar-se doutores e bacharéis.

Julgo desnecessário multiplicar os exemplos do papel crucial representado pela pintura de Debret para o estudo da vida brasileira nas primeiras décadas do século XIX. Esse é também o século de invenção da fotografia, que fornece subsídios adicionais para a representação do 
negro. Não custa relembrar a importância da nova técnica, logo elevada à condição de arte. Entre os teóricos, Kristine Stiles chama a atenção para o discurso fotográfico como "lócus de uma complexa intertextualidade, cuja especificidade está inextricavelmente enredada nos fatos sociais."” Numa linha semelhante, Julia Straub menciona estudos relativos ao impacto da fotografia sobre a maneira de perceber a realidade. Acrescenta que, na atualidade, as teorias da intermidialidade consideram a literatura e a fotografia

[...] mídias para autorreflexão e a autoexpressão, cruciais para a construção da memória e da identidade cultural. [...]. Assim, em seu início, tanto na Grã-Bretanha como nos Estados Unidos, a fotografia se voltou para os excluídos, mostrando as favelas, os pobres nas fábricas, nas ruas ou em miseráveis habitações. Com isso, oferecia uma visão panorâmica da sociedade que a muitos pareceu mais sincera e "honesta" que, por exemplo, representações pictóricas dos mesmos temas. ${ }^{8}$

Essas ponderações não excluem advertências contra uma visão ingênua da fotografia como registro puramente objetivo da realidade. $\mathrm{Na}$ introdução ao livro de Maria Beatriz Coelho, Imagens da Nação, Heloisa Pontes sustenta que, longe de ser um "registro objetivo da realidade", as fotografias - em especial aquelas que ostentam poderosa assinatura autoral - pela escolha do corte (tanto no tempo como no espaço), da composição, do enquadramento, das áreas que devem ficar claras ou escuras - são uma

7 “[...] photographs are texts inscribed in the photographic discourse, but photographic discourse, like any other, is the site of a complex intertextuality, an overlapping series of previous texts $[\ldots]$ at a particular cultural and historical conjuncture $[\ldots]$ inextricably caught up within the specificity of the social acts" (STILES. Language and Concepts. p. 854).

8 "Theories of intermediality today look at literature and photography (among others) as important media of cultural self-reflection and self-expression, vital for the building of cultural memory and identity [...] Thus, both in Britain and the United States, photography often turned to the socially deprived, showing slums, the poor in the factories and streets or shabby housing conditions, thereby opening up a panoramic view of society that struck many viewers as more sincere and 'honest' than, for instance, paintings of similar subjects." (STRAUB. Nineteenth-century Literature and Photography, p. 158, tradução minha). 
interpretação, uma "reconstrução que organiza, hierarquiza e valoriza uma parte do mundo visível". ${ }^{9}$ Contudo, a autora não nega ao livro de Maria Beatriz Coelho um aspecto subjetivo e avaliador, em que a fotógrafa cede o passo à socióloga: "Se a fotografia não é o registro fiel da realidade, do mundo visível, ela é uma forma de representação deste mundo, característica de um período determinado da história." 10

Atenta a essas observações, e em busca de fotos de negros no século XIX, recapitulo alguns fatos sobre a introdução da fotografia no Brasil. Como se sabe, Joseph Nicéphore Niépce (1765-1833) registrou a primeira foto em 1826. A nova técnica foi logo adotada por D. Pedro II, um de seus grandes incentivadores. Provavelmente o primeiro brasileiro a produzir daguerreótipos, o Imperador inaugurou no Brasil o papel de fotos como "luz dos historiadores futuros". ${ }^{11}$

Em Sobrados e mucambos, Gilberto Freyre observa que a transição do retrato pintado para o daguerreótipo e a fotografia coincide com a fase de passagem da sede de poder das casas-grandes rurais para os sobrados urbanos. Nas palavras de Freyre os "artistas do Daguerreotypo" "nos deram os primeiros grandes do império - homens, senhoras e mesmo meninos - imagens, na verdade, exatas, em contraste com vários dos retratos ou das pinturas dos séculos coloniais." 12 Os escravos também eram retratados, não por sua importância como indivíduos, mas como exemplos da "estética do exótico", na expressão de Ana Maria Mauad..$^{13}$ Fotos reproduzidas nos jornais mostram imagens de negros de troncos curvados pela fadiga, olhar embaçado, rostos desfigurados por queimaduras, costas laceradas por açoites. Entretanto, considerando meu interesse especial pela representação da mulher negra, seleciono apenas duas fotos, ilustrativas de duas formas acessíveis às escravas de minorar sua condição: primeiramente, a daquela que, como amante, caía nas boas graças do senhor, e, em segundo lugar, a da ama de leite, que veio a ser conhecida como a "mãe preta".

Considero inicialmente a existência de cativas sedutoras - as "Chicas da Silva"-, que certamente pontuaram a história da escravidão.

\footnotetext{
${ }^{9}$ PONTES. Introdução, p. 22.

${ }^{10}$ PONTES. Introdução, p. 22. Ver também COELHO. Imagens da nação, p. 49, 114.

${ }^{11}$ MAUAD. Imagem e auto-imagem do Segundo Reinado, p. 185.

${ }^{12}$ FREYRE. Sobrados e mucambos, p. 482.

${ }^{13}$ MAUAD. Imagem e auto-imagem do Segundo Reinado, p. 203.
} 
A propósito, lembro algumas observações de Gilberto Freyre. Em Sobrados e mucambos, Freyre discorre sobre a propalada atração sexual dos senhores brancos por negras e mestiças. O sociólogo delega ao bom senso popular e à sabedoria folclórica a crença no poder afrodisíaco de mulatas. ${ }^{14}$ Pelo modo de andar, de sorrir, de olhar, pelo cheiro da carne, pela habilidade dos dedos em cafunés e agrados íntimos, elas exerceriam sobre os brancos uma sedução que as conduziria da miserável condição de escravas aos privilégios de amante, chegando a ameaçar a posição da esposa legítima. A propósito, Robert W. Slenes relata um caso real, documentado em cartório. Em 1887, em Vassouras, província do Rio de Janeiro, a fazendeira D. Maria José pede o embargo de sua propriedade e de seu marido Antônio, a fim de propor contra ele uma ação de "separação perpétua de pessoa e bens". Acusa Antônio de ter dissipado sua fortuna e de adultério com certa Marcelina, ex-escrava e mucama, que o marido libertara para viver com ele na corte. Como prova, Maria José apresenta uma carta de Antônio e uma fotografia de Marcelina, entregues pelo representante comercial no Rio, encarregado de remeter a correspondência com a amante. Transcrevo algumas linhas da carta:

\section{Marcelina,}

Você como tem passado meu bem? Estou com muitas saudades de Você, e ainda não fui dar-lhe um abraço porque estou na roça, feitorando outra vez [...] Adeus, minha negra, recebe um abraço muito e muito saudoso, e até breve. O frio está apertando, e faz-me lembrar das noites da barraca com uma saudade que me põe fora de $\operatorname{mim}[\ldots]^{15}$

A correspondência inclui uma carte de visite, pequeno retrato comum na época, destinado a amigos como lembrança. Vale a pena consultar a imagem de Marcelina. A foto mostra a ex-escrava numa pose típica. Ereta, expressão facial serena, Marcelina tem nas mãos um leque, acessório do traje elegante, que pouco deveria ao das damas imperiais. A mise-en-scène é também sugestiva: consiste na pintura de uma árvore frondosa, como em retratos de D. Pedro II e da imperatriz Teresa Cristina. O conjunto revela a caprichosa técnica do fotógrafo, que, em papel semelhante ao de um diretor de cena, escolhe a iluminação e os ângulos

\footnotetext{
${ }^{14}$ FREYRE. Sobrados e mucambos, p. 466-467.

${ }^{15}$ SLENES. Senhores e subalternos no Oeste paulista, p. 266.
} 
mais favoráveis, orientando a modelo, como para uma performance teatral. Pelo visto, a relação da ex-escrava com Antônio parece ter sido consensual, e não desprovida de afeto, pelo menos da parte do homem. Como chegar às razões de Marcelina? Cálculo? Gratidão? Amor? Um misto de tudo isso? Sabemos apenas que a mulher certamente avaliaria as vantagens da união. Conhecia, por outro lado, as represálias a uma recusa, desde a retração de favores até o castigo físico.

O retrato da antiga escrava faz pensar no citadíssimo poema "Essa negra fulô", de Jorge de Lima (1895-1953). Recuando no tempo, o excerto abaixo inclui uma reconstituição ficcional do momento em que, ao ser açoitada, uma escrava nua, ancestral imaginária de Marcelina, desperta a paixão do senhor:

O sinhô foi ver a negra

Levar couro do feitor.

A negra tirou a roupa.

O Sinhô disse: Fulô!

(A vista se escureceu

Que nem a negra Fulô.)

Essa negra Fulô!

Essa negra Fulô!

-Ó Fulô? Ó Fulô?

Cadê meu lenço de rendas

Cadê meu cinto, meu broche,

Cadê meu terço de ouro

Que teu Sinhô me mandou?

Ah! Foi você que roubou.

Ah! Foi você que roubou. ${ }^{16}$

O momento de sedução imaginado pelo poeta, inspirou também a arte modernista de Pierre Chalita (1930-2010). No quadro Nega fulô, o pintor representa o próprio autor do poema homônimo, usando um terno moderno, junto a uma negra nua, de formas opulentas. Esse

${ }^{16}$ LIMA. Essa negra fulô, p. 25 
entrelaçamento de história, literatura e pintura sugere que o mito da mulata sedutora perdura no imaginário contemporâneo.

Se o papel de amantes como a Marcelina histórica foi uma forma de defesa contra o doloroso cotidiano da mulher escrava, outro, talvez mais frequente, ou, pelo menos, mais registrado em fotografias, foi o de ama de leite. Em Casa-grande \& senzala, Gilberto Freyre menciona tradições sobre o lugar de honra ocupado pela mãe preta no seio das famílias:

\begin{abstract}
Alforriadas, arredondavam-se quase sempre em pretalhonas enormes. Negras a que se faziam todas as vontades: os meninos tomavam-lhes benção: os escravos chamavam-nas de senhoras; os boleeiros andavam com elas de carro. Em dia de festa quem as visse, anchas e ganjentas entre os brancos da casa, havia de supô-las senhoras bem-nascidas, nunca escravas vindas da senzala. ${ }^{17}$
\end{abstract}

No epílogo do segundo volume de História da vida privada no Brasil, Luiz Felipe Alencastro reproduz a foto de uma dessas escravas. ${ }^{18}$ Vale a pena conferir a imagem. Trata-se de um cartão de visita tirado por Augusto Gomes Leal, no estúdio de João Ferreira Villela, em Recife, por volta de 1860, também reproduzido à página 223 de Casagrande \& senzala. A escrava, ereta, exalando uma doçura digna, encara serenamente a câmera. Inclinado, um menino branco se aconchega a ela. A ama traja um vestido elegante, com pregas afofadas em torno do decote, valorizado por longo colar. Segundo o costume da época, joia e vestido são certamente empréstimos da patroa. Provavelmente destinada à parede de uma casa rica, a foto busca sugerir a generosidade dos senhores. Mas o que salta aos olhos é o amor da mãe vicária pelo filho que não gerou. Amor paradoxal, fundado na violência, mas evidente no abraço do menino, agarrado ao braço da mucama. "Quase todo o Brasil cabe nessa foto", conclui Alencastro. ${ }^{19} \mathrm{Na}$ mesma linha, retratos semelhantes, espalhados pelas mídias eletrônicas, fazem pensar em outro poema famoso, "Irene no céu", de Manoel Bandeira (1886-1968), novamente evocando a aliança entre literatura, história e arte..$^{20}$

\footnotetext{
${ }^{17}$ FREYRE. Casa-grande \& senzalaI, p. 435.

${ }^{18}$ ALENCASTRO. Epílogo, v. 2, p. 468-469.

${ }^{19}$ ALENCASTRO. Epílogo, v. 2, p. 440.

${ }^{20} \mathrm{Em}$ trabalho em andamento considero as respostas de dois outros poetas aos poemas citados. Em “Outra nega fulô”, de Oliveira Silveira (1941-2009), a escrava, após tentá-
} 
Irene no Céu

Irene preta

Irene boa

Irene sempre de bom humor.

Imagino Irene entrando no céu:

- Licença, meu branco!

E São Pedro bonachão:

- Entra, Irene. Você não precisa pedir licença. ${ }^{21}$

Confrontando-o com outros textos, os leitores são levados a concordar que essa visão idílica da ama de leite deve-se à idealização das relações entre negros e brancos, apontada por críticos na obra de Gilberto Freyre. Segundo relata Miriam Moreira Leite, visitantes estrangeiros descreveram de forma bem diferente a condição da mãe preta, muitas vezes obrigada a separar-se do próprio filho para atender à criança branca. Em 1872, o suíço Charles Pradez, residente no Rio de Janeiro, escreveu sobre os anúncios de aluguel de amas de leite publicados no Jornal do Comércio: "cada linha representa um drama íntimo, a história de uma cruel separação [...] cada anúncio significa lágrimas, luto e desespero. Apesar disso o interesse pesa sobre essas coisas e outras, pois cada uma corresponde de 120 a 150 francos por mês." 22

A propósito, Miriam Leite, estudiosa de fotografias de família, observa que os retratos de amas de leite apresentam tão somente a imagem positiva do relacionamento afetivo da ama, vestida à europeia, com o bebê branco ao colo:

[...] a prática da amamentação por escravas alugadas a particulares ou asilos de crianças abandonadas foi responsável por uma das formas mais sinistras de interrelacionamento no grupo de convívio. Além de privar os filhos de seu leite, as amas de leite eram exploradas

\footnotetext{
lo com sua nudez, mata o senhor e vai se deitar com um negro. Em outro poema, "O que não dizia o poeminha do Manuel", Márcio Barbosa (1959-) imagina a mãe preta chegando ao céu, quando chama São Pedro de racista e o manda para o inferno.

${ }^{21}$ BANDEIRA. Irene no céu, p. 220.

${ }^{22}$ LEITE. Retratos de família, p. 69.
} 
ao máximo, tanto quando eram alugadas a instituições para amamentar diversas crianças, como pelo período prolongado que se exigia que amamentassem [...] numa relação [...] penetrada pelas condições ambíguas de dependência e violência entre as mães, as amas de leite e as crianças. ${ }^{23}$

Evidentemente, a chaga da escravidão não lacerou apenas a vida social de nosso país. Alastrou-se por outras sociedades, denunciada por historiadores, secundados por artistas, que, em nossos dias, recorrem a mídias inovadoras. No Brasil, destaco o trabalho de Adriana Varejão, e, nos Estados Unidos, a obra conjunta de Dipti Desai (artista e professora de arte na Universidade de Nova York), Rachel Mattison (historiadora, professora na State University de Nova York) e Jessica Hamlin (dedicada ao estudo da ligação entre a arte contemporânea e o ensino da história na escola pública). Na introdução a seu livro History as Art, Art as History (A história enquanto arte, a arte enquanto história) as autoras lembram o quanto artistas contemporâneos podem contribuir para a reconstrução do passado. ${ }^{24}$ Como exemplo, citam uma exposição na Maryland Historical Society de Baltimore, em 1992. Nessa ocasião, o curador Fred Wilson, historiador e artista, registrou uma ruptura radical com exposições tradicionais em museus históricos. Nos arquivos da própria sociedade, selecionou pinturas, peças de mobiliário, utensílios domésticos, capazes de suscitar perguntas instigantes sobre sua função no passado. Wilson organizou um conjunto denominado Mining the Museum (Garimpando o museu), constituído por objetos colocados em justaposições inesperadas.

Entre outras, a instalação Cabinetmaking ${ }^{25}$ (Mobiliário de madeira) convida à comparação com uma obra de Debret. Nessa instalação icônica Wilson dispôs diversas cadeiras emprestadas pelo acervo do museu. A pouca distância, colocou um antigo pelourinho onde, no século XIX, se amarravam escravos norte-americanos enquanto eram açoitados. A função de tortura é destacada pela trave horizontal, que lembra os braços de uma cruz. Da parede, uma etiqueta aludia ao longo período (18201860) em que prevaleceu a punição por chicoteamento. As cadeiras,

\footnotetext{
${ }^{23}$ LEITE. Retratos de família, p. 69-70.

${ }^{24}$ DESAI; MATTISON; HAMLIN. History as Art, Art as History, p. 3.

${ }^{25}$ Ver INSTALLATION view: "Cabinetmaking, 1820-1960". Clique sobre o título para acessar [N.E.].
} 
de estilos diferentes, todas vazias, colocadas em círculos fronteiros ao pelourinho, lembravam o desaparecimento dos privilegiados, que, no conforto insolente de seus assentos, assistiram impassíveis a práticas execráveis. Graças à aliança entre a história e a arte, a denúncia a velhas injustiças sobrevive a seus praticantes.

A instalação de Fred Wilson, tão distante no tempo e no suporte adotado, sugere ao espectador de nossos dias um diálogo com a aquarela de Debret, Pelourinho. Destacado pela posição no centro do quadro, aparece um negro seminu, de pés e mãos atados, com as nádegas expostas ao látego do feitor. Deitados no chão, veem-se outros negros à espera de sua vez de ser açoitados. Os espectadores, dispostos em círculo, como as cadeiras vazias da instalação de Fred Wilson, assistem ao sádico espetáculo. Entretanto, como os aristocratas do passado, não aparentam incômodo ou compaixão.

$\mathrm{Na}$ pós-modernidade, a pintura de Debret vem sendo relida por outros artistas, explorando meios diversos, como nas instalações de Fred Wilson. Refiro-me, sobretudo, à artista brasileira Adriana Varejão (1964-). Sua obra confirma que a arte pode contribuir para contestar a história oficial. A artista usa e abusa de releituras de Debret, que, simultaneamente, cita e contradiz. Conhecedora de estudiosos da história e da literatura, como Sérgio Buarque de Holanda, Gilberto Freyre e Alfredo Bosi, Varejão usa referências à arte do passado para criar uma espécie de contra-história, um contradiscurso desafiador de clichês da narrativa tradicional. Apropriando-se do estilo do pintor francês e debuxando figuras semelhantes às dele, Varejão transporta-os para cenários diferentes, de forma a atribuir-lhes novos sentidos. Sua iconografia incorpora estratégias recorrentes, como rasgões e suturas nas telas, imagens e cores típicas, imitações de azulejos encontrados em monumentos históricos. Sob a ótica dos Estudos de Intermidialidade, essas práticas mostram-se duplamente interessantes: por um lado, questionam o discurso da mídia verbal em textos de historiadores; por outro, recorrem a uma relação intramidiática, em que a pintura questiona a própria pintura.

Nesse questionamento, interessam-me, particularmente, as representações de militares e sacerdotes em suas relações com os escravos. Nas obras de Debret, esses dois braços da colonização - o leigo e o religioso - aparecem exercendo suas atribuições. Padres ministram a extrema unção, presidem a batizados e casamentos. Militares participam de cerimônias 
oficiais e até de festas populares. A ousada recriação de Varejão oferece representações totalmente antagônicas. Numa única obra - o óleo sobre tela intitulado Filho bastardo ${ }^{26}$ - a artista contesta o relacionamento supostamente pacífico desses personagens com mulheres negras.

Usando imagens inspiradas nas inocentes criações de Debret, Filho bastardo, com personagens vestidos à moda da época, contradiz brutalmente uma imagem inserida na memória coletiva brasileira: a de missionários virtuosos, como o jesuíta espanhol José de Anchieta (15341597). Imagem icônica, proclamado Apóstolo do Brasil, foi canonizado pelo Papa Francisco em 2014. Para os cultores dessa tradição, a arte de Varejão chega a ser blasfema. O padre representado à esquerda de Filho bastardo está estuprando uma negra. Alheio ao crucifixo pendente de sua batina, dá sua contribuição para povoar o país com bastardos mestiços. A tela é dividida por uma das marcas da arte de Varejão: uma incisão, semelhante a uma vagina sangrenta, em referência ao estupro de escravas. À direita do corte, é a vez de desmentir a imagem de militares pacíficos, representados nas aquarelas de Debret: um oficial, identificado pela farda, dá as costas à cena. Sua atenção volta-se para uma índia indefesa, amarrada a uma árvore, à espera do mesmo destino da negra violentada.

Resta observar que o trabalho de Varejão lembra que, além de cerimoniais da corte e cenas populares, Debret se interessou pela representação de indivíduos dos vários grupos étnicos do Brasil oitocentista. Entre as mulheres brancas, seu pincel pousa sobre damas da corte, com penteados ornados de plumas e vestidos arrastando caudas portentosas. Retrata também escravas, entregues a tarefas domésticas, ou, na rua, vendendo flores, quitandas e frutas. Não faltam desenhos igualmente famosos de índias, como o de uma jovem que, orgulhosa, exibe um diadema floral, e estufa os seios fartos, realçados por um vistoso colar. Reportandose, talvez, a essas imagens, Adriana Varejão combina esses tipos femininos numa obra única, Testemunhas oculares X, Y, e Z. ${ }^{27}$ Nesse trabalho, a artista inclui seu próprio retrato, triplicado, que remete às mulheres de diversas etnias denominadas de X, Y e Z. Em testemunho de sua identificação com elas, Varejão delegou a Ana Moura, artista acadêmica, a tarefa de

\footnotetext{
${ }^{26}$ Ver o verbete "Filho bastardo" da Enciclopédia Itaú Cultural de arte e cultura brasileiras. Clique sobre o título da imagem para acessar [N.E.].

${ }^{27}$ Ver PAZETO. Instalação na arte contemporânea. Clique sobre o título para acessar [N.E.].
} 
pintar seu retrato em três poses diferentes: como negra, como índia e como uma branca de feições achinesadas (fruto provável de casamentos mistos), lembrando a chinoiserie frequente no barroco brasileiro. Esse tipo de retrato remonta a um gênero colonial praticado na América espanhola, onde casais de raças diferentes costumavam encomendar retratos de si próprios junto aos filhos mestiços, com informações sobre suas etnias escritas na tela. Testemunhas oculares $X, Y$ e $Z$ alude também a uma lenda segundo a qual a imagem do agressor permanece gravada na retina da vítima. Isso explica a fenda no rosto de cada mulher, mostrando o lugar de onde foi extraído um dos olhos. À frente de cada retrato, numa superfície de vidro sustentada por uma moldura de metal, encontra-se uma lente de aumento - que permite ao espectador examinar um pequeno objeto representando o olho arrancado. $\mathrm{O}$ objeto também funciona como um minúsculo porta-joias. Levantada, a tampa deixa ver uma miniatura de gravuras de Theodore de Bry que ilustraram livros do mercenário Hans Staden sobre suas viagens pelo Brasil do século XV. A história de Staden é uma das famosas narrativas sobre canibais nas terras do Novo Mundo - histórias usadas para legitimar a violência da conquista. Não admira que, conforme sugere a instalação de Varejão, os culpados tenham querido mutilar as mulheres estupradas, impossibilitálas de denunciar os abusos sofridos. Nisso, contudo, os criminosos não tiveram êxito. No rosto de cada mulher, um olho, contendo a imagem do agressor, permanece intacto. A vítima pode fixá-lo no espectador, apelar silenciosamente para seu apoio. Surradas e violentadas, essas mulheres viram seus maridos, irmãos e filhos assassinados ou escravizados. A arte, entretanto, lhes prolongou a vida. Na obra de Varejão sua história continua a ser contada. Por outro lado, ao incluir sua própria imagem em três versões, a artista, sugerindo sua identificação com as etnias representadas, acena para um ideal igualitário, no qual as discriminações raciais tenham sido finalmente eliminadas. 


\section{Referências}

ALBERTI, Leon Battista. On Painting. Tradução, introdução e notas de John R. Spencer. rev. New Haven, CT: Yale University Press, 1966. Book II, p. 62-85.

ALENCASTRO, Luiz Felipe. Epílogo. In: . História da vida privada no Brasil Império: a corte e a modernidade nacional. São Paulo: Companhia das Letras, 1997. v. 2, p. 468-469.

BANDEIRA, Manuel. Gilberto Freyre, poeta. In: GILBERTO Freyre: sua ciência, sua filosofia, sua arte. Ensaios sobre o autor de Casa-grande \& senzala, e sua influência na moderna cultura do Brasil. Rio de Janeiro: José Olympio Editora, 1962. p. 79-84.

BANDEIRA, Manuel. Irene no céu. In: Libertinagem: poesia completa e prosa. Rio de Janeiro: Editora Nova Aguilar, 1986. p. 220.

BARBOSA, Márcio. O que não dizia o poeminha do Manuel. Cadernos Negros, São Paulo, v. 15, p. 64, 1992.

CHALITA, Pierre. Nega fulô. Pintura, óleo sobre tela. Publicado por blogmundoa no Instagram, 3 jun. 2016. Disponível em: <https://www. instagram.com/p/BGQiQAdtA5I/>. Acesso em: 23 maio 2017.

COELHO, Maria Beatriz. Imagens da nação: brasileiros na fotodocumentação de 1940 até o final do século XX. Belo Horizonte: Editora UFMG; São Paulo: Imprensa Oficial do Estado de São Paulo, Edusp, 2012. p. 19-31.

DEBRET, Jean-Baptiste. Castigo de escravo. Pintura. Disponível em: $<$ http://historiahoje.com/wp-content/uploads/2014/06/0021.jpg $>$. Acesso em: 30 abr. 2018.

DEBRET, Jean-Baptiste. Pelourinho. 1835. Pintura, aquarela. Disponível em: $<$ https://rrupta.files.wordpress.com/2012/10/pelourinho-jeanbaptiste-debret.jpg $>$. Acesso em: 23 fev. 2018.

DEBRET, Jean-Baptiste. Um jantar brasileiro. 1827. Pintura. Disponível em: <http://3.bp.blogspot.com/__gbSllND7bM/TpVoKzTPedI/ AAAAAAAAAHU/QWZ6FA_G3Xc/s1600/JantarBrasil.jpg $>$. Acesso em: 24 mar. 2018. 
DESAI, Dipti; HAMLIN, Jessica; MATTSON, Rachel. History as Art, Art as History: Contemporary Art and Social Studies Education. New York: London: Routledge, 2010.

FILHO bastardo. In: ENCICLOPÉDIA Itaú Cultural de arte e cultura brasileiras. São Paulo: Itaú Cultural, 2018. Verbete da enciclopédia. Disponível em: $<$ http://enciclopedia.itaucultural.org.br/obra9053/filhobastardo>. Acesso em: 10 fev. 2018.

FREYRE, Gilberto. Casa-grande \& senzala: formação da família brasileira sob o regime da economia patriarcal. 48. ed. Recife: Fundação Gilberto Freyre, 2003.

FREYRE, Gilberto. Sobrados e mucambos: decadência do patriarcado rural e desenvolvimento do urbano. 1. ed. digital. São Paulo: LeLivros. link, 2013.

INSTALLATION view: “Cabinetmaking, 1820-1960". Maryland Historical Society. Baltimore, [c1992-1993]. Disponível em: $<$ http://www. mdhs.org/digitalimage/installation-view-cabinetmaking-1820-1960>. Acesso em: 30 abr. 2018.

LEITE, Miriam Moreira. Retratos de família. 3. ed. São Paulo: EDUSP, 2001.

LIMA, Jorge de. Essa nega fulô. In: . Poemas negros. Rio de Janeiro: Alfaguara, 2016, p. 25.

LINS, Osman. Breve contribuição a um possível estudo acerca da influência de Gilberto Freyre sobre a literatura brasileira. In: GILBERTO Freyre: sua ciência, sua filosofia, sua arte. Ensaios sobre o autor de Casagrande \& senzala, e sua influência na moderna cultura do Brasil. Rio de Janeiro: José Olympio Editora, 1962. p. 306-311.

MAUAD, Ana Maria. Imagem e auto-imagem do Segundo Reinado. In: ALENCASTRO, Luiz Felipe (Org.). História da vida privada no Brasil Império: a corte e a modernidade nacional. São Paulo: Companhia das Letras, 1997. v. 2, p. 181-245.

MÜLLER, Jürgen E. Intermidialidade revisitada: algumas reflexões sobre os princípios básicos desse conceito. In: DINIZ, Thaïs Flores Nogueira; VIEIRA, André Soares (Org.). Intermidialidade e estudos interartes: desafios da arte contemporânea. Belo Horizonte: Programa de Pós- 
Graduação em Estudos Literários, Faculdade de Letras da UFMG, 2012. v. 2, p. 75-95.

PAZETO, Elizabete. Instalação na arte contemporânea. Arte para Todos, 30 jul. 2017. Disponível em: $<$ https://betedeartes.blogspot.com/2015/03/ instalacao-na-arte-contemporanea.html $>$. Acesso em: 30 abr. 2018.

PONTES, Heloisa. Introdução. In: COELHO, Maria Beatriz. Imagens da nação: brasileiros na fotodocumentação de 1940 até o final do século XX. Belo Horizonte: Editora UFMG; São Paulo: Imprensa Oficial do Estado de São Paulo, Edusp, 2012. p. 19-31.

PORTELLA, Eduardo. Gilberto Freyre e a renovação do romance brasileiro. GILBERTO Freyre: sua ciência, sua filosofia, sua arte. Ensaios sobre o autor de Casa-grande \& senzala, e sua influência na moderna cultura do Brasil. Rio de Janeiro: José Olympio Editora, 1962. p. 400-404.

SILVEIRA, Oliveira. Outra nega fulô. Cadernos negros: os melhores poemas, São Paulo, p. 109-110, 1998.

SLENES, Robert W. Senhores e subalternos no Oeste paulista. ALENCASTRO, Luiz Felipe (Org.). História da vida privada no Brasil Império: a corte e a modernidade nacional. São Paulo: Companhia das Letras, 1997. v. 2, p. 233-306.

STILES, Kristine. Language and Concepts. In: STILES, Kristine; SELZ, Peter (Ed.). Theories and Documents of Contemporary Art: A Sourcebook of Artist's Writings, Berkerley, Los Angeles: University of California Press, 1996. p. 804-816.

STRAUB, Julia. Nineteenth-century Literature and Photography. In: RIPPLE, Gabrielle (Ed.). The Handbook of Intermediality: Literature, Image, Sound, Music. Boston, Beijing: De Gruyer Mouton, 2015. p. 152176. doi: https://doi.org/10.1515/9783110311075-010

VERMEER, Johannes. The Art of Painting. [entre 1662 e 1668]. Pintura, óleo sobre tela, $120 \times 100 \mathrm{~cm}$. Disponível em: $<\mathrm{http}: / / \mathrm{www}$. essentialvermeer.com/catalogue_xl/xl_art.html\#.XApfPGhKiM8>. Acesso em: 20 fev. 2018.

Recebido em: 3 de maio de 2018. Aprovado em: 20 de outubro de 2018. 